\title{
Por Trás da Ação Governamental: panorama da estrutura e do FUNCIONALISMO PÚBLICO ${ }^{1}$
}

Sheila Barbosa²

Tatiana Silva ${ }^{3}$

Felix Lopez ${ }^{4}$

\section{INTRODUÇÃO}

Nosso propósito neste texto é condensar alguns aspectos relevantes do debate público sobre a estrutura organizacional da administração federal e do funcionalismo público brasileiro, com ênfase nas dimensôes que constaram na agenda de pesquisas conduzidas pela Diretoria de Estudos e Políticas do Estado, das Instituiçóes e da Democracia (Diest) do Ipea ao longo da última década.

Os aspectos mencionados configuram a organização da ação governamental, a qual é, entre outros fatores, determinante do sucesso na oferta de bens e serviços à sociedade. Em reconhecimento à relevância do tema, a Diest vem realizando estudos e pesquisas relacionados às características e às transformaçóes nas estruturas e na força de trabalho do Poder Executivo federal, de modo a produzir reflexôes sobre sua dinâmica e condicionantes e, assim, contribuir para melhor qualificar tanto o debate acerca das reformas administrativas quanto os processos de transformações incrementais.

Esse empreendimento continua em pauta e recentemente expandiu seu foco para a construção de conhecimento sobre administraçôes públicas dos entes subnacionais, com a produção de bases de dados, em especial o Atlas do Estado Brasileiro, o qual já disponibiliza consultas on-line de dados a respeito da administraçáo pública nos âmbitos federal, estadual e municipal.

Os temas aqui abordados estão entrelaçados a fim de fornecer um panorama geral acerca da trajetória da máquina pública (estrutura e funcionalismo), bem como lançar luzes sobre aspectos pouco explorados quanto às características de composição de sua burocracia. Dessa forma, a próxima seção trata da trajetória e das características das estruturas organizacionais na administração pública federal; a seçáo 3 explora aspectos da força de trabalho no setor público nacional e, no âmbito federal, aspectos da burocracia decisória de médio e alto escalão; e a seção 4 aborda tópicos para compor um inventário de temas pouco discutidos no debate sobre o setor público, tais como as características sociodemográficas desse setor, a representação ativa e passiva na burocracia e questôes correlatas.

\section{ESTRUTURAS ORGANIZACIONAIS NO PODER EXECUTIVO FEDERAL}

A estrutura organizacional da administraçáo pública federal, elemento componente da capacidade estatal, ${ }^{5}$ apresenta trajetória marcada por fragmentação temática e crescente complexidade, considerando

1. DOI: http://dx.doi.org/10.38116/bapi29art7

2. Especialista em políticas públicas e gestão governamental na Diretoria de Estudos e Políticas do Estado, das Instituições e da Democracia

(Diest) do Ipea; e professora adjunta no Departamento de Gestão de Políticas Públicas da Universidade de Brasília (UnB).

3. Técnica de planejamento e pesquisa na Diest/lpea.

4. Técnico de planejamento e pesquisa na Diest/lpea.

5. Destacam-se os esforços de Pires e Gomide (2014), que nesta edição abordam a trajetória e propõem avanços nos estudos sobre capacidades estatais. 
que o número de ministérios avançou de dez para quarenta nos períodos democráticos entre 1946 e 2015. A maior diversificação temática está na distribuição de competências, quer seja por reflexos da complexificação de demandas da sociedade, quer seja por influência do sistema político na construção de coalizões de governo (Barbosa, 2019; Barbosa e Pompeu, 2017; Borges e Barbosa, 2019). Tal trajetória agrega ao contexto desafios de coordenação da ação governamental entre diferentes setores de atuação e seus centros decisórios.

A percepção desse contexto produziu reflexos na produção de conhecimentos acerca do tema na última década, tanto na Diest como na produção geral do Ipea, seja pelo investimento em construção de bases de dados, seja pela promoção de estudos relacionados ao tema.

A partir de diferentes abordagens, vários estudos apontam tendências quanto à capacidade organizacional em distintas perspectivas, sobretudo no nível federal. Uma visão de conjunto, sobre tal produção e seus achados, é sintetizada aqui pelo foco nas relaçôes político-administrativas, nas relaçóes entre a administração pública e a sociedade, bem como na sua dinâmica interna (estrutura e força de trabalho).

$\mathrm{Na}$ abordagem das relaçóes político-administrativas, a Diest promoveu, nos anos recentes, a construção de bases de dados sobre a organização da administração pública federal, as quais permitiram a Borges e Barbosa (2019) reconstruir e discutir a trajetória de ocupação partidária de ministérios nas posiçóes de ministros ou cargos de mesmo status na hierarquia do Poder Executivo federal. Viabilizando reflexôes acerca da influência do sistema político sobre a estrutura do Poder Executivo federal, os dados deste estudo sugerem uma correlação entre os tamanhos de coalizóes de governo e movimentos de expansão ou retração dessa estrutura no que se refere a número de ministérios/órgãos ou cargos com status de ministério e ministro, respectivamente. De modo geral, quanto maior a coalizão, maior o tamanho da estrutura ministerial (gráfico 1).

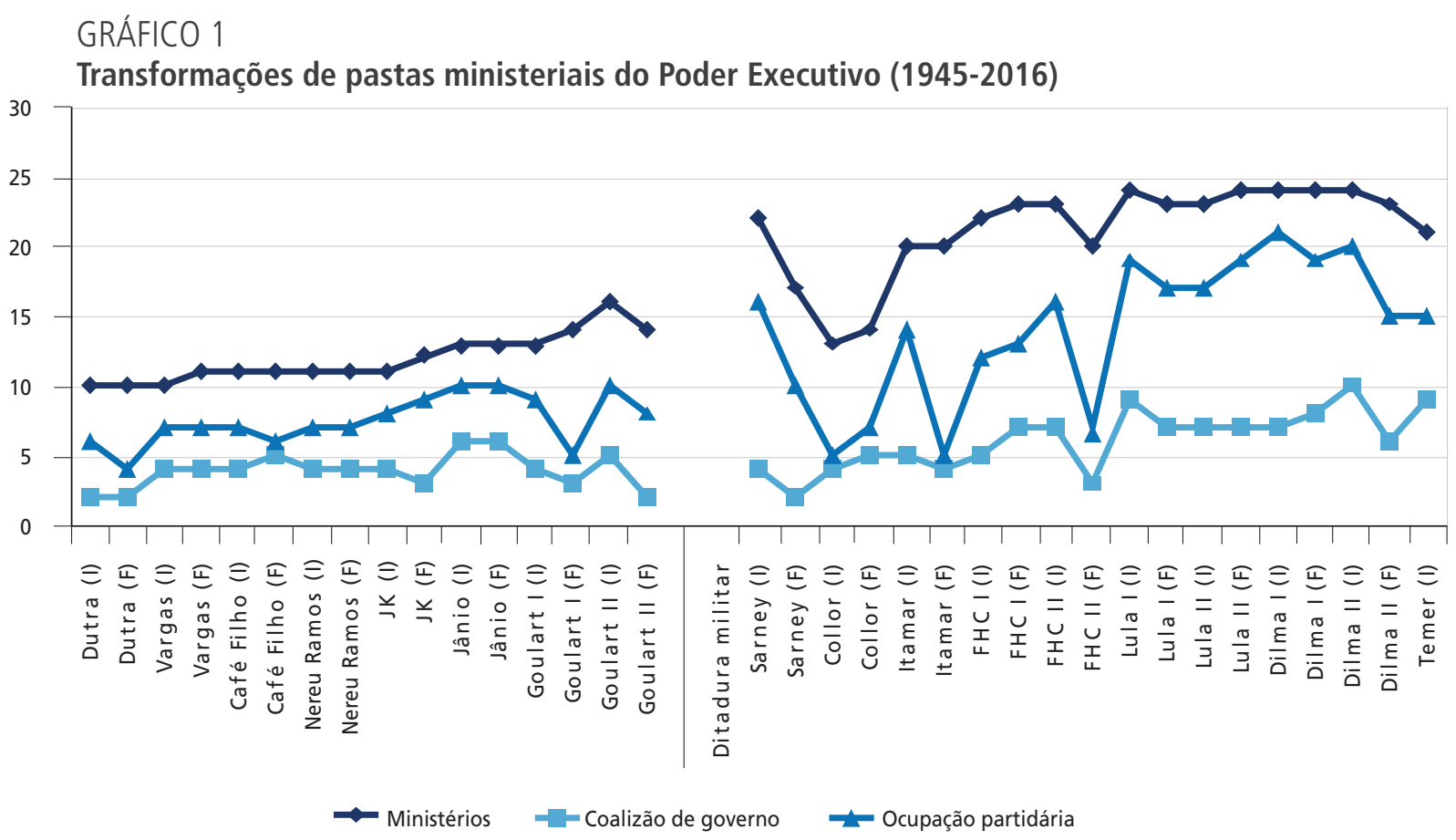

Fonte: Borges e Barbosa (2019).

Obs.: (I) - Formação inicial; (F) - Formação final. 
Silva e Barbosa (2019) evidenciam um padrão de nichos de ocupação partidária por setores de políticas públicas, o que sugere que a estrutura organizacional do Poder Executivo federal mais se assemelha a um arranjo influenciado pelo sistema político do que a um resultado de escolhas técnicas sobre formas de atuação. ${ }^{6} \mathrm{O}$ estudo destaca ainda a ocorrência de coalizóes mais amplas entre 2003 e 2015, acompanhadas de estratégia de expansão da estrutura, com padrão de ocupação dos setores social e de governo pelo partido do presidente. Outro ponto destacado foi a observação da presença do Partido do Movimento Democrático Brasileiro (PMDB) em todos os governos, mais concentrada em pastas do setor de infraestrutura.

A observação mais atenta dos dados a respeito dos cargos revela nuances da mencionada influência do sistema político sobre a estrutura. Se, por um lado, os movimentos de redução das coalizóes de governo acompanhados de corte do número de ministérios apontados no gráfico 1 sinalizam redução na estrutura organizacional, por outro lado, os dados do número de cargos no nível de direção (gráfico 2) sinalizam que a estrutura não reduz de fato, corroborando o que Barbosa e Pompeu (2017) denominaram movimentos de aglutinação de ministérios conservando estruturas abaixo do cargo de ministro. Sobre isso, destaca-se que o número de cargos de confiança, ou seja, aqueles de livre provimento e exoneração, que configuram recurso de poder no interior do sistema político e definem as linhas horizontais e verticais da estrutura organizacional (divisão temática e divisão hierárquica, respectivamente), expressa contínuo crescimento com um aumento de, aproximadamente, 60\% no total de DAS 5 e 6 (Direção e Assessoramento Superior) entre 1999 e 2016 (gráfico 2).

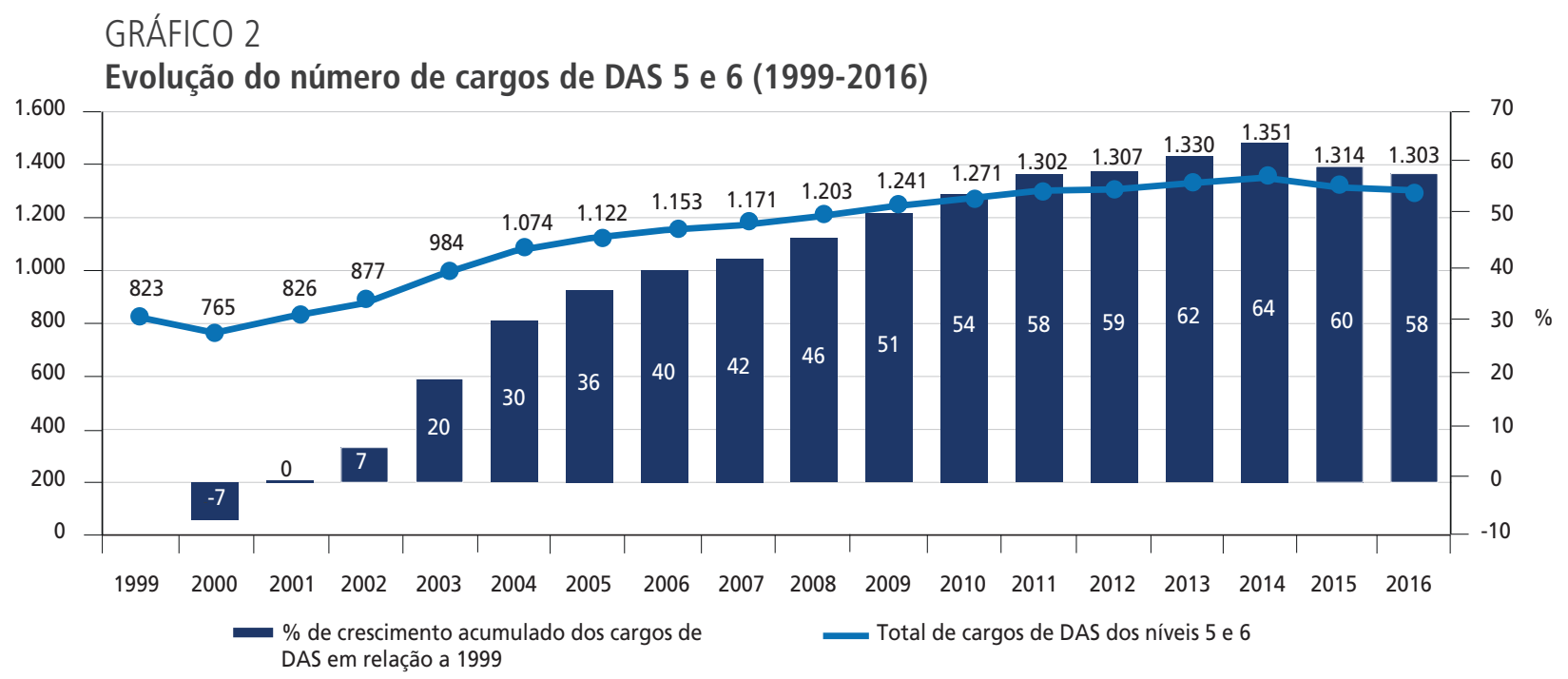

Fonte: Painel Estatístico do Ministério da Economia 2020.

No que se refere às relações entre a administração pública e a sociedade, a literatura aponta o investimento na democratização da gestão, mediante a criação de espaços de participação social na gestão pública, desde os anos 1990 por meio de distintas interfaces. Pires e Vaz (2012) exploram a ampliação dos tipos e volumes de interação entre estado e sociedade, entre eles, os conselhos de políticas públicas, as conferências, audiências públicas, reunióes com grupos de interesse e canais

6. Observação também sinalizada por Ryu, Moon e Yang (2019, p. 3 e 5) em reorganizações administrativas de trinta países da Organização para a Cooperação e Desenvolvimento Econômico (OCDE). 
via internet. Entre estas formas de interação, do ponto de vista organizacional, destaca-se a seguir e em particular a trajetória dos conselhos de políticas públicas e das ouvidorias, visto que compóem a estrutura administrativa dos governos.

Em relação aos conselhos de políticas públicas, Avelino, Alencar e Costa (2017) demonstram sua expansão desde o fim dos anos 1990 e de forma mais intensa a partir de 2003. Quanto às ouvidorias no governo federal, Cardoso (2010) apresenta sua expressiva ampliaçáo, que salta de 40 em 2002 para 285 em 2014. A complexidade organizacional torna-se entáo cada vez mais desafiadora, posto que os processos de gestão passam a refletir o interesse na participação social e incluem articulação, consulta e construção de consensos em arenas de debate e decisão com atores externos aos quadros da administração pública.

No âmbito da dinâmica interna, cujo foco é a análise das estruturas organizacionais e da burocracia, os estudos sobre o Poder Executivo federal, promovidos pelo Ipea, apontam não apenas a tendência de fragmentação organizacional, mas também a pulverização da menor porção dos recursos orçamentários e de mão de obra em um número amplo de ministérios (Barbosa, 2019). Isso se dá em razão da soma de dois aspectos: i) uma fragmentação horizontal observável tanto na ampliação do número de ministérios quanto na ampliação da divisão temática das competências ministeriais; e ii) um contexto de concentração de mais da metade do orçamento (entre $60 \%$ e $70 \%$ ) nos quatro principais ministérios responsáveis pela execução de despesas obrigatórias dos setores de previdência social, saúde, educação e trabalho/emprego.

Quanto aos recursos de mão de obra, a sua distribuição na estrutura organizacional concentra-se em dois setores: Educação e Saúde. As duas pastas respondem, em média, por aproximadamente $60 \%$ total do funcionalismo civil federal. O restante da estrutura organizacional, que chegou a atingir quarenta órgãos com status de ministério, esteve na disputa pelo restante dos recursos organizacionais disponíveis, caracterizando uma pulverização da menor parcela de recursos, tanto de mão de obra quanto de orçamento, em um maior número de órgãos, o que no limite pode induzir a baixas capacidades de implementação de políticas públicas e até mesmo paralisias por deficit de tais recursos (Barbosa, 2019).

Os dados quanto à alocação de recursos organizacionais sinalizam a necessidade de qualificar esse padrão de distribuição, de modo a verificar se ele está associado a peculiaridades das áreas de atuaçáo menos intensivas em mão de obra e/ou se os demais setores utilizam instrumentos de implementação de políticas públicas menos exigentes em termos de tais recursos (Barbosa, 2019).

Para uma compreensão mais detalhada acerca da burocracia pública e desafios para sua gestão e efetividade, são abordados a seguir aspectos de sua composição, cargos e carreiras, bem como as agendas subexploradas e invisíveis.

\section{PESSOAL, CARGOS E CARREIRAS NO FUNCIONALISMO NACIONAL}

O debate da última década sobre o funcionalismo público se concentrou de modo desproporcional em características da força de trabalho em nível federal, o que produziu duas implicaçóes negativas. A primeira foi dissipar esforços de análises empíricas e comparadas sobre os demais segmentos do funcionalismo, que abrangem $90 \%$ da força de trabalho: $60 \%$ dos servidores estão nos municípios e 30\%, nos estados. A segunda implicação negativa foi distorcer o entendimento do perfil de segmentos altamente diversos do funcionalismo nacional, que advém do fato de a burocracia federal 
ser significativamente distinta dos demais níveis federativos, na maioria das métricas relevantes: é mais escolarizada, recebe salários maiores, não se expandiu de modo significativo e exerce funções e atividades diferentes da burocracia implementadora, majoritária nos estados e municípios.

Empreendeu-se um esforço na Diest, ao longo dos anos, para incorporar os demais níveis federativos do Executivo na análise de tendências do setor público e ampliar o horizonte do entendimento sobre o funcionalismo nos níveis federativos. Buscou-se também desconstruir as interpretaçóes de que, nos anos 2000, o funcionalismo teve expansão descontrolada e injustificada, que consumia fatias crescentes do orçamento público (Nogueira e Cardoso Junior, 2011). Demonstrou-se que i) a expansão do funcionalismo federal resultou da recomposição de quadros via seleção meritocrática para regularizar contrataçôes indevidas por meio de terceirização; ii) a contratação se concentrou em ocupaçóes do magistério superior; e iii) o volume de pessoal na União não excedia sequer o tamanho observado no início dos anos 1990.

Um novo esforço para retratar características do funcionalismo em seus diferentes níveis e poderes, de modo mais sistemático e multidimensional, ocorreu recentemente, com dados e análises do Atlas do Estado Brasileiro ${ }^{7}$ (Lopez e Guedes, 2020). A plataforma sistematiza e aponta as significativas diferenças entre segmentos do funcionalismo público. Tais diferenças continuam a ser ofuscadas pela narrativa de um funcionalismo que ganha muito, entrega pouco e se expande sem peias. A cada nova crise fiscal ou proposta de reforma administrativa, essas narrativas ressurgem no debate público.

Em meio a esse lugar-comum do suposto inchaço, aspectos cruciais para aprimorar o desempenho do setor público avançaram pouco na última década e na agenda da própria Diest. Em geral, inexiste uma política nacional de recursos humanos no setor público ou que, ao menos, crie um sistema de avaliação das demandas por novos quadros em diferentes áreas da administração direta e indireta. Há um certo casuísmo quanto à reposição dos quadros da administração pública nacional, e grande parte do recrutamento varia, essencialmente, em função da capacidade de pressão política de órgãos e carreiras no interior do Executivo ou de decisóes autocráticas dos núcleos de governo.

Não houve avanço em estudos - em particular, do nível federal - sobre meios de organizar carreiras, bem como das políticas e incentivos que devem reger a progressão funcional de servidores. Inexistem, como pesquisa e como política pública, propostas visando aprimorar a avaliação de progressão dos servidores em suas carreiras, de ampliação da chamada "amplitude salarial" entre os que entram e os servidores seniores - essencial para a própria ideia de carreira -, além de virtualmente nenhum avanço em meios de racionalizar ou integrar carreiras públicas. $\mathrm{O}$ amplo espaço para conhecer melhor o funcionalismo, por meio de análises empírico-comparadas entre unidades subnacionais, foi pouco explorado e continua a ser uma agenda promissora. O debate reformista centra-se em narrativas generalizantes, em propostas de alteração linear que desconsideram especificidades entre áreas de políticas e níveis de governo, e não concede espaço para incorporar dimensôes não econômicas para qualificar o serviço público.

$\mathrm{Na}$ burocracia decisória, conformada por cargos de livre nomeação, houve algum avanço no entendimento dos padróes de recrutamento, embora restrito ao Executivo federal. Partimos de uma imagem de cargos essencialmente ocupados por nomeaçóes político-partidárias - em particular, em

7. Disponível em: <www.ipea.gov.br/atlasestado>. 
cargos DAS - para a evidência atual de que a influência partidária é mais contida e o espaço das burocracias de carreira, maior (Lopez, 2015). O fato de 12\% dos nomeados para DAS serem filiados a partidos, equivalente ao que se observa entre a população de eleitores, sugere que a politização dos cargos dirigentes é um fenômeno distinto e mais destacado que a partidarização. A ocupação crescente de cargos da burocracia decisória por servidores de carreira é evidência adicional de que os cargos de confiança não são território inteiramente aberto ao controle partidário (Lopez e Silva, 2019). Novamente, uma ampla agenda de compreensão desse fenômeno em nível subnacional está por ser implementada.

Um dos problemas fundamentais da burocracia decisória federal é sua elevada instabilidade. O problema não é tanto a influência partidária na burocracia de médio escalão, mas o fato de a discricionariedade das escolhas descer até níveis intermediários da gestão. Tome-se o fato de um nomeado para cargo DAS do alto escaláo permanecer um período mediano de pouco mais de 21 meses no cargo - e esse tempo não aumenta muito no médio escalão (Lopez e Moreira, 2021). Os efeitos negativos sobre as capacidades de planejar e implementar políticas federais são altos. Um segundo problema é a combinação da instabilidade generalizada nos cargos de confiança e a fragmentação administrativa - aludida na seção anterior -, ampliada pela presença de diferentes partidos lutando por influenciar e controlar posiçóes no interior de um mesmo órgão.

Em suma, e de modo panorâmico, aspectos relativos às trajetórias das estruturas organizacionais do Executivo federal e à composição da força de trabalho no setor público se combinaram para prover um retrato mais realista da administração pública pós-1988, com enquadramento analítico que privilegiou a abordagem entre a esfera administrativa e política. Com essa ênfase, alguns aspectos, em especial os atinentes à dimensáo sociodemográfica da força de trabalho do Estado, permaneceram ausentes da agenda da diretoria e dos estudos sobre o setor público, em geral.

\section{4 À GUISA DE CONTINUIDADE}

Embora o debate sobre a composição da burocracia pública tenha sido abordado em diferentes aspectos, como padrão de remuneração, carreiras, cargos em comissão, tipos de vínculos, eficiência e produtividade, na literatura nacional, muito menos atenção tem sido dispensada à análise sobre quem ocupa os cargos públicos. Essa lacuna encontra ressonância no Ipea e na Diest, salvo poucas iniciativas (Silva e Silva, 2014; Abreu e Meirelles, 2012). Mais recentemente, a plataforma Atlas do Estado Brasileiro apresentou dados do funcionalismo por sexo e, em 2020, passou a incorporar estatísticas por cor ou raça.

Uma vez que a burocracia não conta com delegação direta da população, a possibilidade de representatividade e, em tese, de maior legitimidade social pode se dar por meio de composição mais igualitária, que represente a população para a qual atua e espelhe interesses plurais nas decisóes governamentais. Essa representatividade pode se expressar de modo passivo, no sentido de correspondência estatística dos diversos grupos populacionais, ou ainda de modo ativo, quando os burocratas atuam na conformação de políticas públicas e serviços de modo a atender especificidades dos públicos que representam. Essa atuação encontra, na discricionariedade administrativa e na identificação social dos atores, variáveis-chave. Além dessas, importa destacar a representatividade simbólica, quando a presença de determinados grupos estimula a identificação dos cidadãos, a predisposição para coprodução ou a confiança em políticas e serviços públicos (Kennedy, 2013; Meier, 2019). 
Em uma sociedade que tem historicamente suas desigualdades estruturais sedimentadas no estatuto do silêncio sobre vibrantes violências, a presença de determinados segmentos, como negros, mulheres, LGBTQIA+, indígenas, entre outros, em postos de destaque e direção já corresponde a eloquente manifesto. Desse modo, compreender os mecanismos por meio dos quais operam, sob aspecto de neutralidade, os múltiplos meios de discriminação direta e indireta que conduzem a resultados desiguais na ocupação de cargos e carreiras é frente necessária e alvissareira de análise profunda da burocracia nacional.

A discriminação positiva tem sido uma das iniciativas mobilizadas a fim de promover mais representatividade burocrática (Volpe e Silva, 2016). Para que as políticas afirmativas, como a reserva de vaga para negros em concursos públicos, sejam efetivas, é necessário ainda conjugá-las com outras camadas de proposiçôes relativas aos domínios disciplinar e hegemônico (Colins, 2000). Sua efetividade está frontalmente condicionada à assunção do problema racial e de outras desigualdades estruturais ao centro da atenção e diligência da administração pública, estabelecendo o enfrentamento ao racismo, sexismo, homofobia, entre outros, como cerne de projeto de justiça social operado por uma burocracia que experimente, profundamente, esses princípios em sua composição e, sobretudo, em seu funcionamento e atuação.

Ainda sobre a composição da força de trabalho no setor público, importa destacar o papel da terceirização. Premido pela ampliação de suas atribuiçóes e pelos limites fiscais para contratação de pessoal, o Estado, em seus diferentes níveis e poderes, tem recorrido à terceirização como meio para não apenas ampliar seus serviços, como essencialmente manter atividades básicas. Nesse contexto, em 2015, em 85\% dos municípios brasileiros se afirmava contar com assessoria externa, especialmente nas áreas contábil e jurídica. Na prestação direta de serviços, por sua vez, em igual percentual, contava-se com serviço terceirizado em, pelo menos, uma das seguintes áreas: "segurança dos prédios da prefeitura, iluminação pública, limpeza urbana e coleta de resíduos sólidos domiciliar, hospitalar e industrial” (IBGE, 2015, p. 29). A terceirização das atividades tem sido forma corrente de flexibilização organizacional, protagonizando intensos debates e alteraçóes legislativas (Barbosa, 2019), além de insegurança, dificuldades de coordenação e precarização das relaçóes de trabalho no âmbito da administração pública. Desse modo, a terceirização é campo de conhecimento sobre a burocracia que ainda tem muito a ser explorado (Campos, 2018).

O enfrentamento às desigualdades e à discriminação não é passível de compartimentação, em departamentos e instâncias, como se a estas, isoladamente, coubesse efetivar tão desafiadoras mudanças. Não é excepcional que ainda se acusem essas estruturas e seus condutores, relegados à margem, dos seus próprios infortúnios. Um projeto dessa envergadura demanda esforços compatíveis. Uma proposição que tenta avançar nesse campo é o conceito da transversalidade, que exige o atravessamento de diretrizes como gênero e raça por todos os programas governamentais. Para isso, demanda espaços de articulação e coordenação das políticas, comprometimento nos níveis de planejamento e orçamento, participação e visibilidade aos diversos grupos sociais. Diante de cenários de desarticulação/fragmentação organizacional e orçamentária, sobreposição de interesses e disputas, não se trata de desafio trivial como campo de pesquisa e intervenção (Silva, 2011). Conquanto suas implicações já tenham sido tratadas na Diest (Avelino, Alencar e Costa, 2017), é certo que sua apreensão demanda esforço prolongado e adensado, a despeito da descontinuidade e superficialidade com que esta perspectiva de coordenaçáo burocrática tem sido tratada no Estado brasileiro, em diferentes níveis (Silva, Cardoso e Silva, 2014). 
Em diálogo com as perspectivas da representatividade e da transversalidade, está a abordagem interseccional, que consiste em buscar meios conceituais e de coordenação que compreendam as diferentes desigualdades não como sobreposição ou adição de vulnerabilidades, mas sim como imbricamento, promovendo experiências individuais e coletivas singulares. Assim, por exemplo, se a simples adição das perspectivas de gênero e raça, isoladamente, não traduz a vivência de mulheres negras (Crenshaw, 2002), as respostas, em termos de políticas públicas, por sua vez, devem observar a complexidade da intersecção desses diferentes eixos de opressão na dinâmica social (Collins, 2000).

\section{CONSIDERAÇÕES FINAIS}

O estudo e o debate sobre a organização da administração pública brasileira e sobre a constituição de sua burocracia têm muito a avançar. Compreender suas relaçóes com o sistema político, com a sociedade e sua dinâmica interna é essencial para ensejar política de gestão pública que considere as implicaçóes das escolhas quanto ao tema sobre a sociedade, bem como possa direcionar transformaçóes para produzir os desejados avanços em eficiência, efetividade, representatividade e responsividade do serviço público.

Investigaçóes sobre o tema constituem agenda tanto mais oportuna na medida em que um processo de transformação contínua da administração pública, sustentado em diagnósticos mais aprofundados, se faz menos visível que reformas administrativas propostas em resposta a crises econômicas e com relevantes lacunas de qualificaçáo de seu contexto de constituição e funcionamento.

\section{REFERÊNCIAS}

ABREU, M. A. A.; MEIRELLES, R. de L. Mulheres e homens em ocupação de DAS na administraçáo pública federal. Brasília: Ipea, 2012. (Relatório de Pesquisa). Disponível em: <http://repositorio. ipea.gov.br/bitstream/11058/7745/1/RP_Mulheres_2012.pdf>.

ALMEIDA, A. Governo presidencial condicionado: delegação e participação legislativa na Câmara dos Deputados. 2018. Unpublished Ph.D. Dissertation - Instituto de Estudos Sociais e Políticos (IESP), Universidade do Estado do Rio de Janeiro, 2018.

AVELINO, D. P. de; ALENCAR, J. L. O.; COSTA, P. C. B. Colegiados nacionais de políticas públicas em contexto de mudanças: equipes de apoio e estratégias de sobrevivência. Brasília: Ipea, 2017. (Texto para Discussão, n. 2340).

BARBOSA, S. C. T. A organização da administração pública e suas implicações sobre a implementação de políticas públicas: o governo federal. In: ARRETCHE, M.; MARQUES, E. As políticas da política: desigualdades e inclusão nos governos do PSDB e do PT. Editora Unesp, 2019.

BARBOSA, S. C. T.; CARDOSO JUNIOR, J. C. (Org.). Boletim de Análise Político-Institucional. Brasília: Ipea, n. 12, 2017. Disponível em: <https://bit.ly/3lybXLS>.

BARBOSA, S. C. T.; POMPEU, J. C. Trajetória recente da organização do governo federal. Boletim de Análise Político-Institucional, Brasília: Ipea, n. 12, 2017. 
BORGES, J. da S.; BARBOSA, S. C. T. Ministérios como 'barganha': coalizão de governo e organização do Poder Executivo. Revista do Serviço Público, v. 70, n. 2, p. 267-296, 2019.

CAMPOS, A. G. (Org.). Terceirização do trabalho no Brasil: novas e distintas perspectivas para o debate. Brasíla: Ipea, 2018. Disponível em: <https://www.ipea.gov.br/portal/index.php?option=com_ content\&view=article\&id=32326>.

CARDOSO, A. S. R. Ouvidorias públicas e democracia. In: SÁ E SILVA, F.; LOPEZ, F.; PIRES, R. (Org.). Estado, instituiçóes e democracia: democracia. Brasília: Ipea, 2010. p. 211-228.

COLLINS, P. H. Black feminist thought: knowledge, consciousness, and politics of empowerment. New York/London: Routledge, 2000.

COSTA, M. M.; ALVES, M. A.; GOMES, M. V. P. Cotas de acesso ao serviço público e burocracia representativa na cidade de São Paulo. In: ENCONTRO DE ADMINISTRAÇÃO PÚBLICA E GOVERNANÇA, 2016, São Paulo. Anais...São Paulo: ANPAD, 2016.

CRENSHAW, K. Documento para o encontro de especialistas em aspectos da discriminação racial relativos ao gênero. Estudos Feministas, ano 10, 2002.

ENAP - ESCOLA NACIONAL DE ADMINISTRAÇÃO PÚBLICA. Capacidades estatais para produçáo de políticas públicas: resultados do survey sobre serviço civil no Brasil. Brasília: Enap, 2018. (Cadernos, n. 56).

FAIRCLOUGH, N. Discurso e mudança social. 2. ed. Brasília: Editora UnB, 2016.

FERREIRA, M. A. C. Burocracia de Estado e políticas de promoção da igualdade racial. 2014. 276 f. Tese (Doutorado) - Universidade de Brasília, Brasília, 2014.

IBGE - INSTITUTO BRASILEIRO DE GEOGRAFIA E ESTATÍSTICA. Pesquisa de informaçóes básicas municipais. Perfil dos municípios brasileiros - 2015.

KENNEDY, B. A. Sorting through: the role of representation in bureaucracy. Journal of Public Administration Research and Theory, v. 23, n. 4, p. 791-816, 2013. DOI: 10.1093/jopart/mut028.

LOPEZ, F. (Org.). Cargos de confiança no presidencialismo de coalizáo brasileiro. Brasília: Ipea, 2015.

LOPEZ, F.; GUEDES, E. Três décadas de evolução do funcionalismo público no Brasil (1986-2017). Brasília: Ipea, 2020. (Texto para Discussão, n. 2579).

LOPEZ, F.; MOREIRA, T. O carrossel burocrático dos cargos de confiança: análise de sobrevivência dos cargos de direção (DAS) do Executivo federal brasileiro (1999-2017). Revista Dados, 2021. No prelo.

LOPEZ, F.; SILVA, T. Filiações partidárias e nomeações para cargos da burocracia federal (1999-2018). Revista de Administraçáo Pública, v. 53, n. 4, p. 711-731, 2019. Disponível em: $<$ https://bit.ly/35vyPGe>.

MEIER, K. J. Theoretical frontiers in representative bureaucracy: new directions for research. Perspectives on Public Management and Governance, v. 2, n. 1, p. 39-56, 2019.

NOGUEIRA, R.; CARDOSO JUNIOR, J. C. (Org.). Burocracia e ocupação no setor público. Rio de Janeiro: Ipea, 2011. 
PALOTTI, P. Estratégias de seleçáo e substituiçáo de ministros de Estado no presidencialismo de coalizáo brasileiro: perfil, alocação e rotatividade. Tese (Doutorado) - Universidade de Brasília, Brasília, 2017. Disponível em: <https://repositorio.unb.br/handle/10482/23620>.

PIRES, R. R.; GOMIDE, A. A. Análise comparativa: arranjos de implementação e resultados de políticas públicas. In: GOMIDE, A. A.; PIRES, R. R. (Ed.). Capacidades estatais e democracia: arranjos institucionais de políticas públicas. Brasília: Ipea, p. 351-379, 2014.

PIRES, R.; VAZ, A. Participaçáo social como método de governo? Um mapeamento das "interfaces socioestatais” nos programas federais. Rio de Janeiro: Ipea, 2012. (Texto para Discussão, n. 1707).

RYU, L.; MOON, M. J.; YANG, J. The politics of government reorganizations: evidence from 30 OECD countries, 1980-2014. Governance, 2019. DOI: 10.1111/gove.12458.

SILVA, J. M. da; CARDOSO, M. do R. de H. C.; SILVA, T. D. Planejamento, orçamento e a promoçáo da igualdade racial: reflexóes sobre os planos plurianuais 2004-2007 e 2008-2011. Brasília: Ipea, 2014. (Relatório de Pesquisa).

SILVA, N. da; BARBOSA, S. C. T. Trajetória da ocupaçáo partidária nos setores temáticos da estrutura do Poder Executivo (1986-2016). Rio de Janeiro: Ipea, 2019. (Texto para Discussão, n. 2453).

SILVA, T. D. Gestão da transversalidade em políticas públicas. In: ENCONTRO DA ASSOCIAÇÃO NACIONAL DE PÓS-GRADUAÇÃO EM ADMINISTRAÇÃO, 35., 2011, Rio de Janeiro. Anais...Rio de Janeiro: Anpad, 2011.

SILVA, T. D.; SILVA, J. M. da. Reserva de vagas para negros em concursos públicos: uma análise a partir do Projeto de Lei 6.738/2013. Brasília: Ipea, 2014.

VIANA, R. R.; TOKARSKI, C. P. Burocracia representativa: uma (re)produção de desigualdades de gênero e raça no setor público federal? NAU Social, v. 10, n. 19, p. 65-84, 2019.

VOLPE, A. P.; SILVA, T. D. Reserva de vagas para negros na administraçáo pública. Brasília: Ipea, 2016. (Relatório de Pesquisa). Disponível em: <https://www.ipea.gov.br/portal/index. php?option=com_content $\&$ id $=27543>$. 